\section{The ore deposit-tectonics connection}

\author{
Frederick J. Sawkins
}

Mineral Deposits and Global Tectonic Settings. By A.H.G. Mitchell and M.S. Garson. Pp.404. ISBN 0-12-499050-9. (Academic: 1982.) £23.60, \$48.50.

With Mineral Deposits and Global Tectonic Settings, Mitchell and Garson are to be congratulated on providing us with a most impressive piece of scholarship. The interrelationships between tectonics and mineral resources have attracted increasing attention from earth scientists during the past decade, and their book represents by far the most competent and complete analysis of the subject which has emerged so far.

With commendable thoroughness the authors deal successively with hotspot and rifting environments, passive margins and continental margins, oceanic settings, subduction environments and collision settings, and finally transform faults, both in terms of their geology and their associated mineral deposits. The subject is approached in a no-frills, workmanlike style and few stones are left unturned, especially with respect to discussion of the various geological sub-environments within the major types of plate boundary settings. The 164 illustrations that accompany the text are, in the main, well chosen and illuminating, and the bibliography is not only extensive, but consists mainly of papers published within the past decade. The treatment is truly world-wide in scope, although the number of examples of geological terrains and mineral deposits taken from Communistbloc countries is understandably rather small.

In view of the foregoing, it is perhaps less than charitable to focus on what I regard as the relatively minor shortcomings of the volume. The great challenge inherent in such an undertaking is the achievement of balance, presumably guided, at least in part, by economic significance. Here the authors' greater experience in Africa and the Far East, as opposed to the Cordillera of North and South America, is discernible. For example, considerable emphasis is placed on alkaline complexes and ophiolites, and important Cordilleran deposits such as polymetallic skarns and epithermal precious metal deposits are given short shrift. Porphyry copper deposits are also dealt with in surprisingly few pages considering their pre-eminent economic importance and well-defined tectonic setting. Also, although tonnage and grade figures are given for some major deposits, the distinction between mere mineral occurrences, small deposits and major orebodies is not at all clear in many instances.

This book, however, represents mandatory reading for anyone interested in mineral deposits-tectonics relationships. It will be a valuable resource to those concerned with any aspect of earth resources, tectonics or, for that matter, the regional geology of our planet.

Frederick J. Sawkins is a Professor in the Department of Geology and Geophysics at the University of Minnesota.

\section{Plants in the sea}

\section{G.E. Fogg}

Marine Botany. By Clinton J. Dawes. Pp.628. ISBN 0-471-07844-1. (Wiley: 1981.) £33.50, \$59.85. The Biology of Seaweeds. Edited by Christopher S. Lobban and Michael J. Wynne. Pp.786. UK ISBN 0-632-00672-2; US ISBN 0-52004585-8. (Blackwell Scientific/University of California Press: 1982.) $£ 45, \$ 85$.

THE plants of the sea are phylogenetically very different from their terrestrial counterparts, and in open waters competitive advantage is with the small rather than with the large and complex as on land. Such differences justify treating marine botany as a distinct discipline but the task of surveying the whole field, including the taxonomy, life histories, biochemistry, physiology and ecology of marine plants, has not often been attempted. However, with the growth of our knowledge of the sea and the extension of our ability to see and handle marine plants in situ provided by SCUBA diving techniques, it is becoming easier to shed preconceived ideas derived from land-based botany and discern general principles.

Marine Botany is such a survey, designed chiefly for the undergraduate student. The author has set out to cover physiology and biochemistry, as well as taxonomic and ecological aspects, but the treatment is mainly descriptive. Thus a conventional account of the various groups of marine algae, of a sort which is available in many other texts, takes up almost half the book. The space left for other topics is not always used to best advantage - a picture of an oxygen meter is not very informative. The single chapter on plankton says nothing of one of its most fascinating aspects - the interplay of buoyancy control and exploitation of water movements which enables this type of organism to live a precarious existence between the darkness of the depths and nutrient starvation at the surface.

Rather better are the chapters on seagrass communities, mangrove swamps and coral reefs, which give accounts of communities not often featured in botanical texts, and that on economic utilization is an up-to-date summary.
There are appendices on marine fungi and bacteria and these, too, contain material which is not readily available elsewhere. A feature of the book is that details of chemical and other techniques and keys for identification for some groups as far as order or genus are given. The author has written a book which will be useful as an introduction, but has rather missed the opportunity to display the beautiful adaptations in form and function of plants to the marine environment.

The Biology of Seaweeds, a multi-author work, is more limited in scope and much more advanced in treatment. It is organized in four sections - on structure and reproduction, ecology, physiology and biochemistry, and seaweeds as resources. The first of these summarizes recent advances in our knowledge of red, brown and green algae. For those already bemused by the intricacies of the life-cycles of red seaweeds these chapters will not help; but that physiologists, biochemists and ecologists must take account of such things is shown in an excellent account of polysaccharides - in which alternation of generations at the biochemical level is described - by the well-supported suggestion that having alternate life-forms better adapts a seaweed to environmental stress, and by casual observations such as that the crustose phase of Scytosiphon lomentaria is less palatable to the snail Littorina littorea than is the foliose plant.

Better understanding of life-cycles has arisen largely from increasing use of laboratory cultures, and cultures are also being used extensively in studies on nutrient uptake, morphogenesis, growth regulators and other biochemical and physiological aspects, while transplantation and other in situ manipulations are now standard techniques for the field ecologist. Paralleling this is the development of methods in mariculture to meet the growing demand for seaweed products in industry. Chapters on geographical distribution, populations, various aspects of seaweed photosynthesis, translocation, chemical constituents and sexuality are all authoritative and thoughtprovoking. A statement that a water movement of $14 \mathrm{~m} \mathrm{sec}^{-1}$ exerts a stress equivalent to that of a gale of 890 miles per hour on land makes one wish that more had been said about the mechanical properties of seaweeds, in particular their relation to the molecular architecture of the cell wall.

However, the study of seaweeds is expanding too rapidly for any survey to be comprehensive. Apart from the proceedings of the ten international seaweed symposia which have now been held, this book is the first major work to bring together knowledge of the various aspects of these marine plants under one cover. It is an important sea-mark in marine botany that will soon be left astern.

G.E. Fogg is Professor of Marine Biology at the University College of North Wales, Bangor. 